Article

\title{
Melatonin Inhibits Apoptosis and Oxidative Stress of Mouse Leydig Cells via a SIRT1-Dependent Mechanism
}

\author{
Gaoqing Xu, Jing Zhao, Hongyu Liu, Jun Wang * and Wenfa Lu * \\ College of Animal Science and Technology, Jilin Agricultural University, Changchun 130118, China \\ * Correspondence: junwang2004@126.com (J.W.); wenfa2004@163.com (W.L.); Tel.: +86-0431-84532936 (W.L.)
}

Academic Editors: Kamelija Zarkovic and Neven Zarkovic

Received: 22 July 2019; Accepted: 24 August 2019; Published: 25 August 2019

\begin{abstract}
The purpose of the present study is to examine the effects of melatonin on apoptosis and oxidative stress in mouse Leydig cells and to elucidate the mechanisms responsible for these effects. Our results indicated that $10 \mathrm{ng} / \mathrm{mL}$ of melatonin significantly promoted cell viability, the ratio of EdU-positive (5-Ethynyl-2'-deoxyuridine) cells, and increased the mRNA expression of proliferating cell nuclear antigen (PCNA), cyclin D1(CCND1), and cell division control protein 42 (CDC42) $(p<0.05)$. We also observed that melatonin inhibited apoptosis of mouse Leydig cells, accompanied with increased B-cell lymphoma-2 (BCL-2) and decreased BCL2 associated X (BAX) mRNA and protein expression. Moreover, addition of melatonin significantly decreased the reactive oxygen species (ROS) production and malondialdehyde (MDA) and 8-hydroxy-2'-deoxyguanosine (8-OHdG) levels, while it increased superoxide dismutase (SOD) and glutathione peroxidase (GSH-Px) levels $(p<0.05)$. In addition, we also found that melatonin increased the expression of SIRT1 (Silent information regulator 1) $(p<0.05)$. To explore the role of SIRT1 signaling in melatonin-induced cells, mouse Leydig cells were pretreated with EX527, an inhibitor of SIRT1. The protective effects of melatonin on mouse Leydig cells were reversed by EX527, as shown by decreased cell proliferation and increased cell apoptosis and oxidative stress. In summary, our results demonstrated that melatonin inhibited apoptosis and oxidative stress of mouse Leydig cells through a SIRT1-dependent mechanism.
\end{abstract}

Keywords: melatonin; apoptosis; oxidative stress; SIRT1; Leydig cells; mouse

\section{Introduction}

Infertility is a medical problem worldwide and approximately half of all cases are caused by male infertility [1]. Several studies have suggested that oxidative stress and apoptosis are important causes of male infertility [2-4]. Leydig cells, which are one of the main cell types in the testis and the primary site for androgen synthesis and secretions, can promote the development of the reproductive organ and spermatogenes in males. Additionally, oxidative stress and apoptosis in Leydig cells are closely related to testicular function [5,6]. Therefore, anti-oxidation and anti-apoptosis supplements are a potential strategy to overcome male infertility.

Melatonin ( $\mathrm{N}$-acetyl-5-methoxy tryptamine) related to both nervous stimulation and endocrine secretion, is mainly produced by the pineal gland, and is also beneficial to the regulation of circadian rhythms [7]. Melatonin is essential to various biological activities, including anti-aging [8], anti-oxidation [9], anti-inflammation [10], anti-apoptosis [11] and anti-pyroptosis [12]. Previous studies have suggested that melatonin could decrease the levels of apoptosis and oxidative stress in a variety of cells, such as granulosa cells [11,13], skeletal muscle cells [14], nucleus pulposus cells [15], and spermatogonial stem cells [16]. In addition, melatonin can directly act on the testis and ameliorate testicular damages caused by oxidative stress, apoptosis, and inflammation [17-20]. Significantly, 
past research has depicted that melatonin reduces testosterone secretion in mouse Leydig cells [21,22]. However, the effects of melatonin on apoptosis and oxidative stress in mouse Leydig cells and its mechanisms have not been examined.

Silent information regulator 1 (SIRT1), a preserved nicotinamide adenine dinucleotide (NAD+) dependent histone deacetylase, plays a crucial function in a variety of molecular mechanisms. Some studies have shown that SIRT1 has protective effects against apoptosis and oxidative stress. For example, activating SIRT1could inhibit the apoptosis induced by hypoxia/reoxygenation in H9c2 cells [23]. Additionally, SIRT1 can fight against oxidative stress by protecting osteocytes and bone precursor cells in order to restitute a normal bone remodeling activity in osteoporosis [24]. SIRT1 deacetylation can activate forkhead box O1 (FoxO1) to synthesize superoxide dismutase (SOD) and Catalase (CAT), resulting in increased cellular resistance to oxidative stress [25]. In addition, melatonin has been a potent regulator of SIRT1 and can regulate apoptosis, oxidative stress, inflammation, and autophagy through the SIRT1 signaling pathway, which is found in cellular or animal models of many diseases [10,26-29]. There is little research on the role of SIRT1 in the absence of pathological conditions. Based on the aforementioned studies, we hypothesized that SIRT1 is engaged in melatonin-regulated apoptosis and oxidative stress in mouse Leydig cells.

Hence, the existing study was conducted to evaluate the protective effects of melatonin against apoptosis and oxidative stress in mouse Leydig cells and the function of SIRT1 signaling in this process.

\section{Results}

\subsection{Melatonin Promoted Proliferation of Mouse Leydig Cells}

First, an MTT assay was used to examine the effect of melatonin on cell viability of mouse Leydig cells. As depicted in Figure 1A, cell viability of Leydig cells treated with 10 and $100 \mathrm{ng} / \mathrm{mL}$ melatonin at $36 \mathrm{~h}$ or $48 \mathrm{~h}$ was enhanced significantly $(p<0.05)$ and the effect at $36 \mathrm{~h}$ was better than that at $48 \mathrm{~h}$. However, there was no significant difference among the five groups at $24 \mathrm{~h}(p>0.05)$. Therefore, treatment with melatonin for $36 \mathrm{~h}$ was selected for the following experiment. Next, we tested the mRNA expression of proliferation related genes, including proliferating cell nuclear antigen (PCNA), cyclin D1 (CCND1), and cell division control protein 42 (CDC42). As shown in Figure 1B-D, 10 ng/mL of melatonin significantly increased the ratio of 5-ethynyl-2'-deoxyuridine (EdU)-positive cells and the mRNA expression of PCNA, CCND1, and CDC42 $(p<0.05)$. These results showed that melatonin promoted proliferation of mouse Leydig cells.

\subsection{Melatonin Inhibited Apoptosis of Mouse Leydig Cells}

We further examined the regulation of melatonin on apoptosis of mouse Leydig cells. First, the apoptosis rate of mouse Leydig cells treated with varying doses of melatonin for $36 \mathrm{~h}$ was detected by flow cytometry analysis. Melatonin at concentrations of 10 and $100 \mathrm{ng} / \mathrm{mL}$ significantly decreased the apoptosis rate of mouse Leydig cells (Figure $2 \mathrm{~A})(p<0.05)$. In addition, when compared with the control group, $10 \mathrm{ng} / \mathrm{mL}$ of melatonin significantly decreased the mRNA and protein expression of BCL2 associated X (BAX), while it enhanced the mRNA and protein expression of B-cell lymphoma-2 (BCL-2) (Figure 2B-D) $(p<0.01)$. Together, these data suggested that melatonin inhibited apoptosis of mouse Leydig cells. 
A

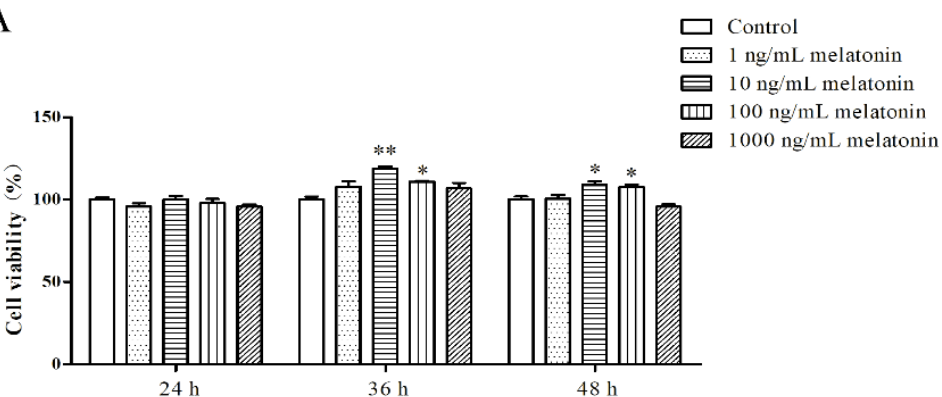

B

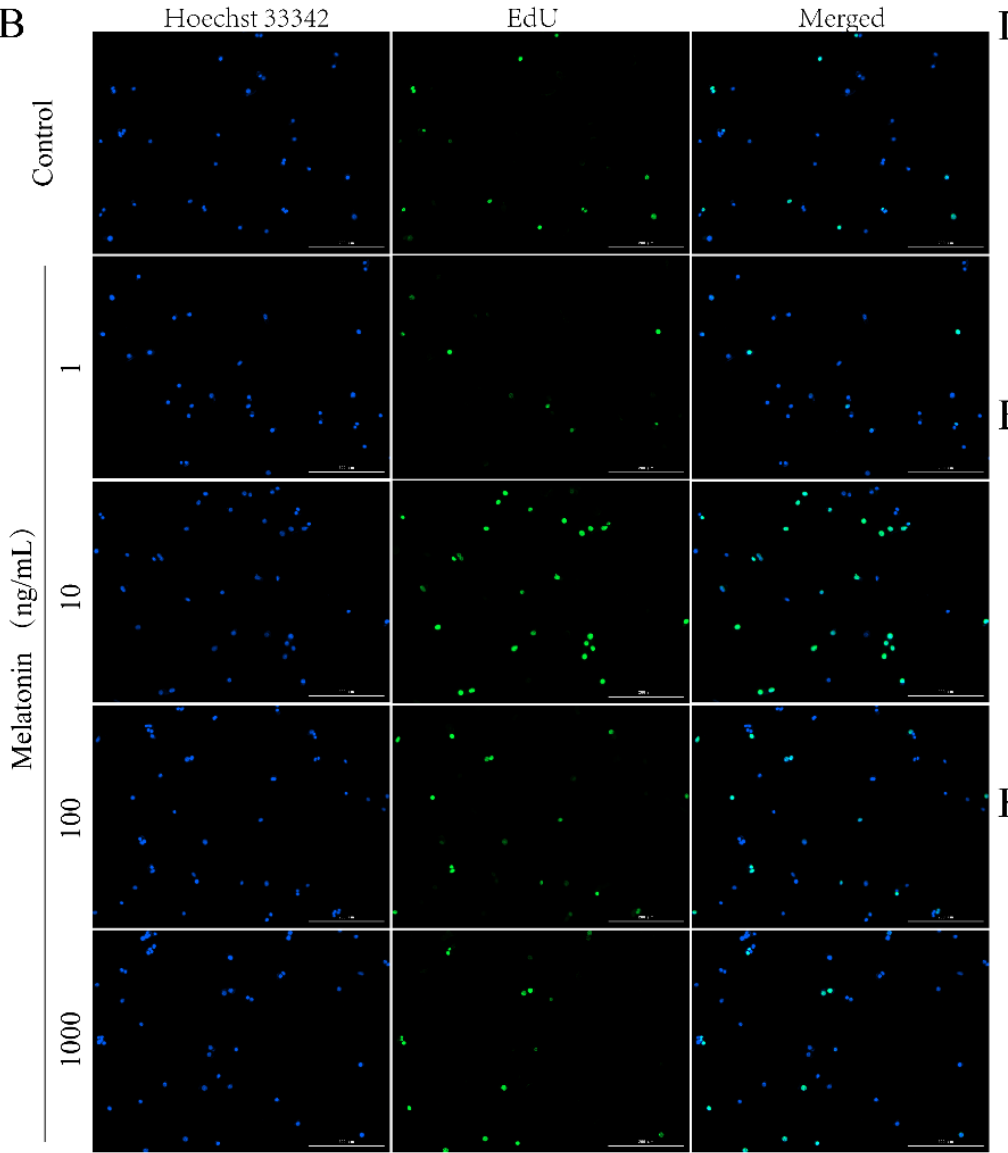

$\mathrm{C}$

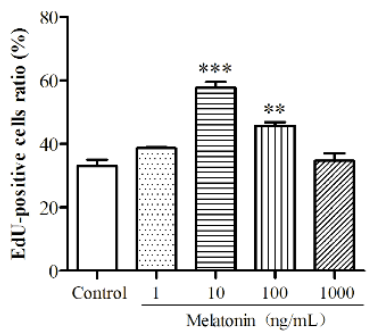

$\mathrm{D}$

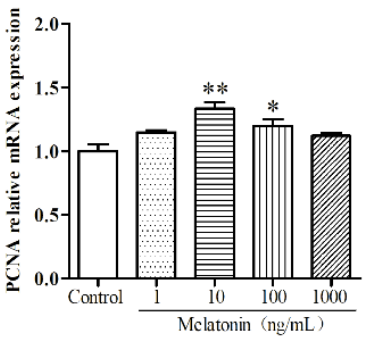

E

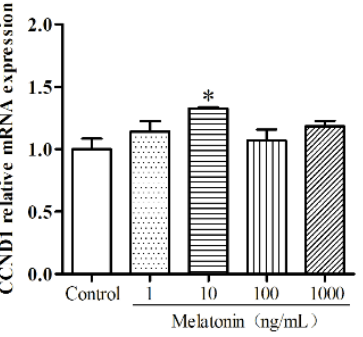

$\mathrm{F}$

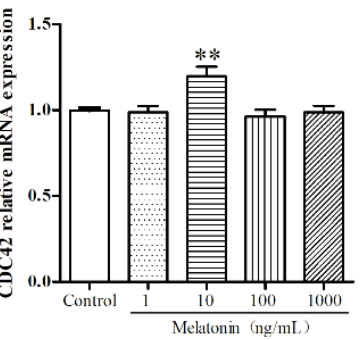

Figure 1. Effects of melatonin on proliferation of mouse Leydig cells. (A) The effects of different concentrations $(1,10,100$, and $1000 \mathrm{ng} / \mathrm{mL})$ of melatonin on the cell viability of mouse Leydig cells at various times $(24,48$, and $72 \mathrm{~h})(n=3)$. (B) Proliferation of mouse Leydig cells treated with different concentrations of melatonin was measured using the EdU incorporation assay $(n=3)$. Green fluorescence represents EdU-labeled Leydig cells (original magnification $\times 10$ ). (C) The proportion of EdU-positive Leydig cells as shown in panel (B). The relative mRNA expression levels of proliferating cell nuclear antigen $(P C N A)(\mathrm{D})$, cyclin D1 (CCND1) (E), and cell division control protein 42 (CDC42) (F) $(n=3)$. Values are shown as mean \pm SEM. ${ }^{* * *} p<0.001$, ${ }^{* *} p<0.01$ or ${ }^{*} p<0.05$ compared with the control group. 

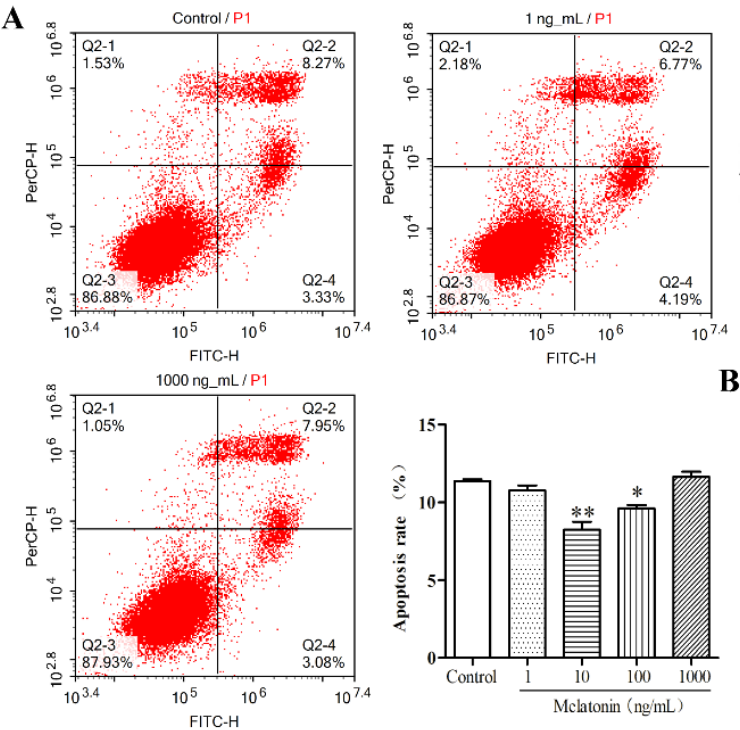

D
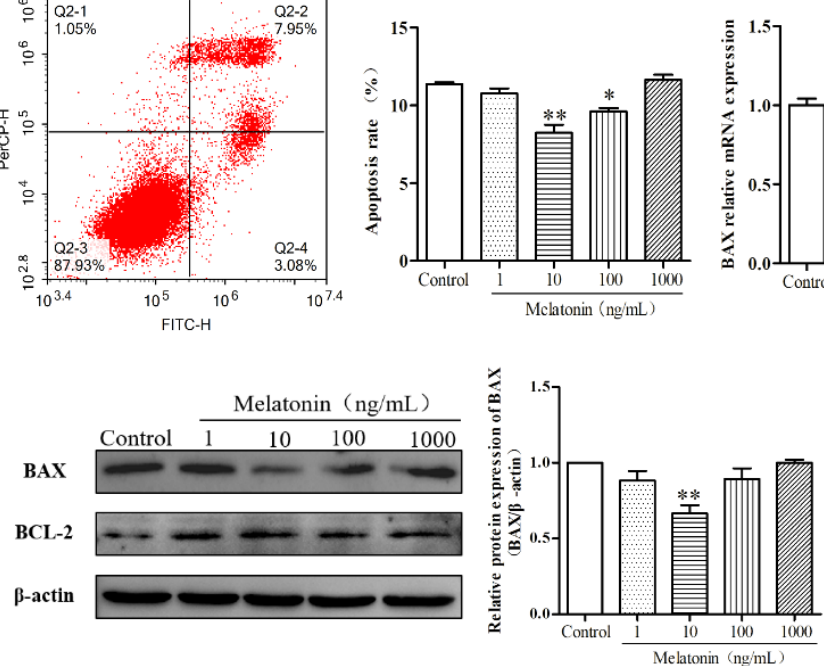

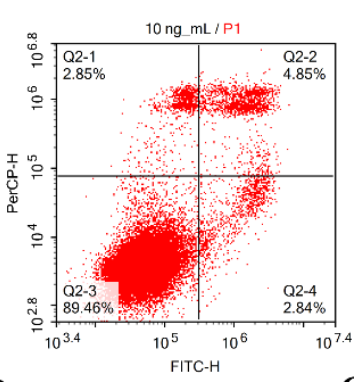

C
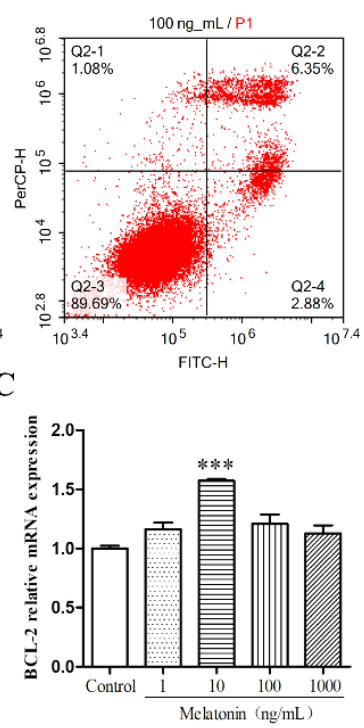

Figure 2. Effects of melatonin on regulating the mRNA and protein expression levels of apoptosis related factor. (A) The effects of different concentrations of melatonin on apoptosis rate of mouse Leydig cells for $36 \mathrm{~h}(n=3)$. The four quadrants in the figure represent dead cells $(\mathrm{Q} 2-1)$, late-stage apoptotic cells (Q2-2), viable cells (Q2-3), and early-stage apoptotic cells (Q2-4). The apoptosis rate is the sum of values from Q2-2 and Q2-4. The relative mRNA expression levels of $B A X(\mathbf{B})$ and $B C L-2(\mathbf{C})(n=3)$. (D) The relative protein expression levels of BAX and BCL-2 were detected and analyzed $(n=3)$. Values are shown as mean \pm SEM. ${ }^{* * *} p<0.001$, $^{* *} p<0.01$ or ${ }^{*} p<0.05$ compared with the control group.

\subsection{Melatonin Suppressed Oxidative Stress of Mouse Leydig Cells}

To examine the effect of melatonin on the oxidative stress of mouse Leydig cells, we detected the levels of reaction oxygen species (ROS), malondialdehyde (MDA), 8-hydroxy-2'-deoxyguanosine (8-OhdG), superoxide dismutase (SOD), and glutathione peroxidase (GSH-Px) in mouse Leydig cells after treatment with various concentrations of melatonin. The results of flow cytometry indicated that melatonin at concentrations of $1,10,100$, and $1000 \mathrm{ng} / \mathrm{mL}$ significantly reduced the fluorescence intensity of ROS $(p<0.05)$ and $10 \mathrm{ng} / \mathrm{mL}$ of melatonin was the best among the three concentrations (Figure 3A). Additionally, MDA (Figure 3B) and 8-OHdG (Figure 3C) levels $(p<0.01)$ decreased significantly, while SOD (Figure 3D) and GSH-Px (Figure 3E) levels increased $(p<0.01)$. These results showed that melatonin inhibited oxidative stress in mouse Leydig cells. 
A

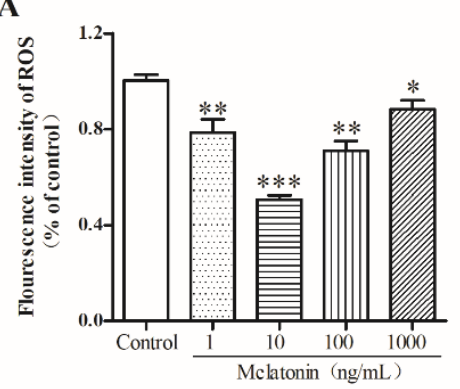

D

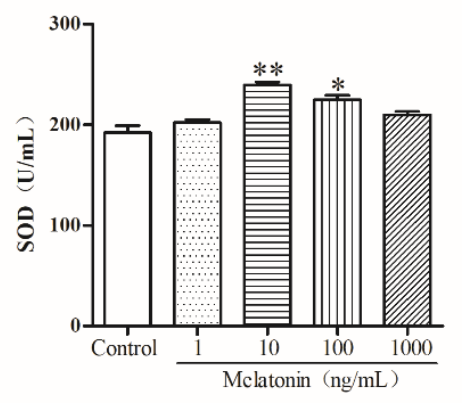

B

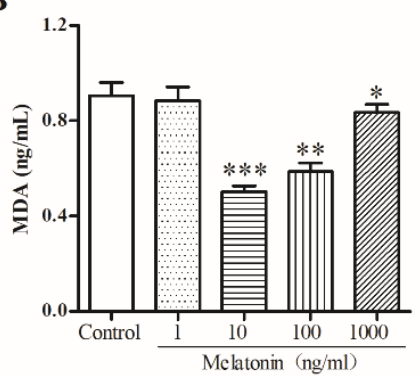

$\mathbf{E}$

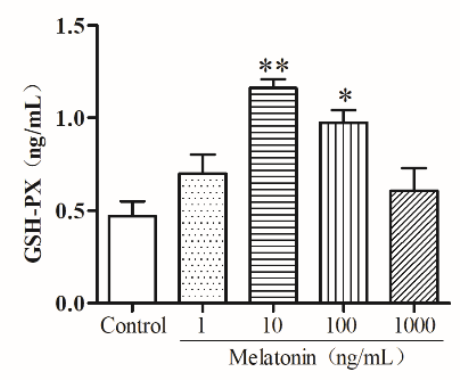

C

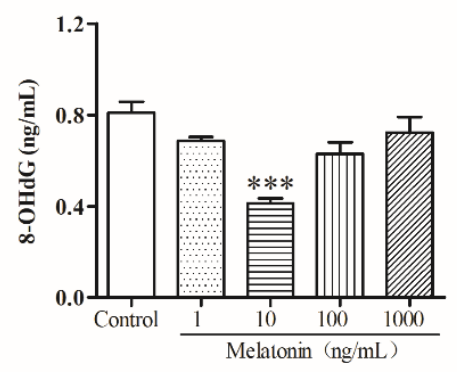

Figure 3. Effects of melatonin on reactive oxygen species (ROS), malondialdehyde (MDA), 8-hydroxy-2'-deoxyguanosine (8-OHdG), superoxide dismutase (SOD), and glutathione peroxidase (GSH-Px) in mouse Leydig cells. (A) The fluorescence intensity of ROS was measured by flow cytometry analysis $(n=3)$. The levels of MDA (B), 8-OHdG (C), SOD (D) and GSH-Px (E) were measured by a microplate reader $(n=3)$. Values are shown as mean \pm SEM. ${ }^{* * *} p<0.001,{ }^{* *} p<0.01$ or ${ }^{*} p<0.05$ compared with the control group.

\subsection{Melatonin Increased Cell Proliferation via a SIRT1-Dependent Mechanism in Mouse Leydig Cells}

Based on the above results, we selected $10 \mathrm{ng} / \mathrm{mL}$ of melatonin to treat mouse Leydig cells for 36 $\mathrm{h}$ for the next experiment. As depicted in Figure $4 \mathrm{~A}, \mathrm{~B}$, melatonin enhanced the mRNA expression of SIRT1 $(p<0.01)$ and the protein expression of SIRT1 $(p<0.05)$. Subsequently, we found that the addition of EX527 reversed the effects of melatonin on cell viability (Figure 4C) and cell proliferation (Figure 4D,E). EX527 pretreatment also reversed the melatonin-induced decrease in PCNA, CCND1, and CDC42 expression (Figure $4 \mathrm{~F}-\mathrm{H})(p<0.05)$. There was no significant difference observed between the control group and the EX527-only treatment group $(p>0.05)$. The above results showed that melatonin could promote the proliferation of mouse Leydig cells via a SIRT1-dependent mechanism.

\subsection{Melatonin Inhibited Apoptosis of Mouse Leydig Cells via a SIRT1-Dependent Mechanism}

As shown in Figure 5A, EX527 significantly relieved the apoptosis rate in mouse Leydig cells decreased by melatonin $(p<0.01)$. Additionally, in the melatonin-only treatment, the mRNA and protein expression levels of BCL-2 were enhanced, while BAX expression was decreased. When the cells were pretreated with EX527 followed by melatonin, the mRNA and protein expression levels of BCL-2 and BAX were comparable to those of the control (Figure 5B-D) $(p<0.05)$. There was no significant difference observed between the control group and the EX527-only treatment group $(p>0.05)$. Taken together, melatonin could inhibit apoptosis of mouse Leydig cells via a SIRT1-dependent mechanism. 


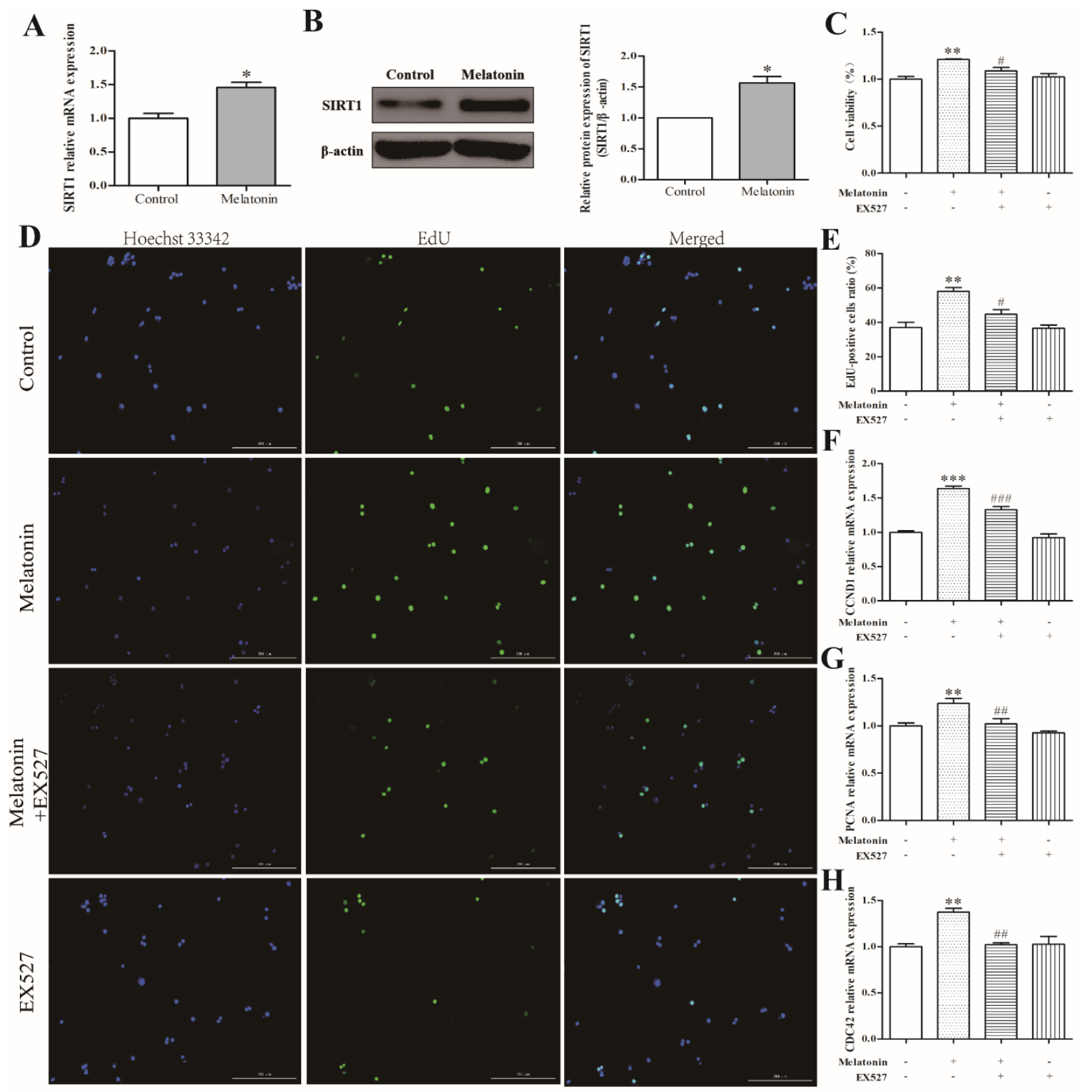

Figure 4. Effects of melatonin and EX527 on cell viability and proliferation related genes of mouse Leydig cells. (A) The mRNA expression level of SIRT1 $(n=3)$. (B) The protein expression level of SIRT1 $(n=3)$. (C) The effects of melatonin and EX527 on cell viability of mouse Leydig cells $(n=3)$. (D) Proliferation of mouse Leydig cells in the control, melatonin, melatonin+EX527, and EX527 groups was measured using the EdU incorporation assay. Green fluorescence represents EdU-labeled Leydig cells (original magnification $\times 10$ ). (E) The proportion of EdU-positive Leydig cells as shown in panel (D). The effects of melatonin and EX527 on mRNA expression levels of CCND1 (F), PCNA (G), and CDC42 $(\mathbf{H})$ in mouse Leydig cells $(n=3)$. Values are shown as mean \pm SEM. ${ }^{* * *} p<0.001,{ }^{* *} p<0.01$ or * $p<0.05$ compared with the control group; \#\#\# $p<0.001$, \#\# $p<0.01$ or \# $p<0.05$ compared with the melatonin-only treatment group. 
A
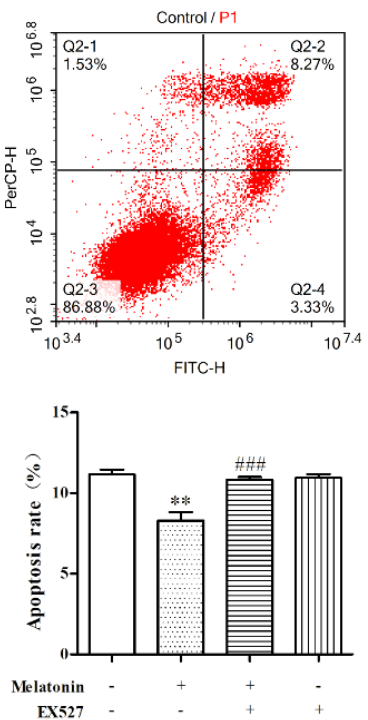

D

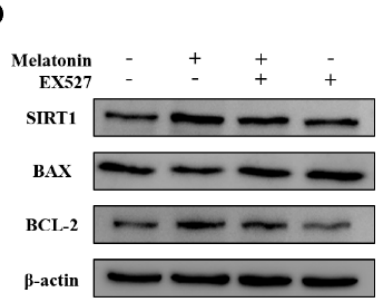

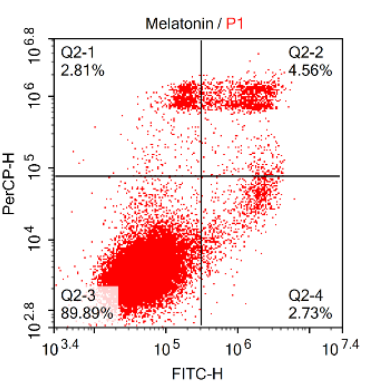

B

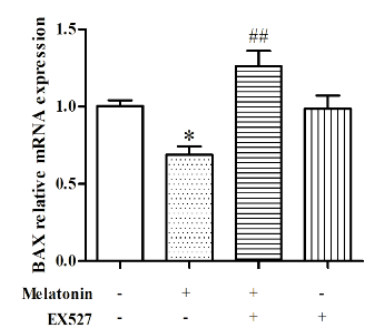

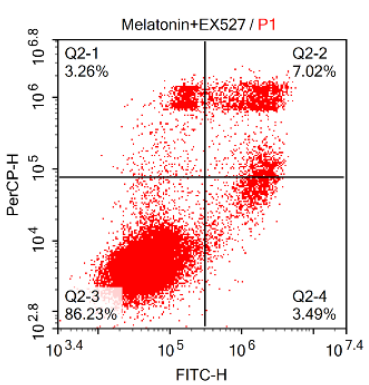

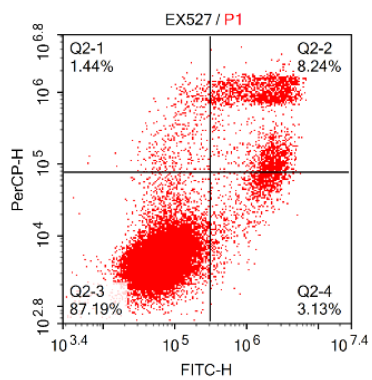

C
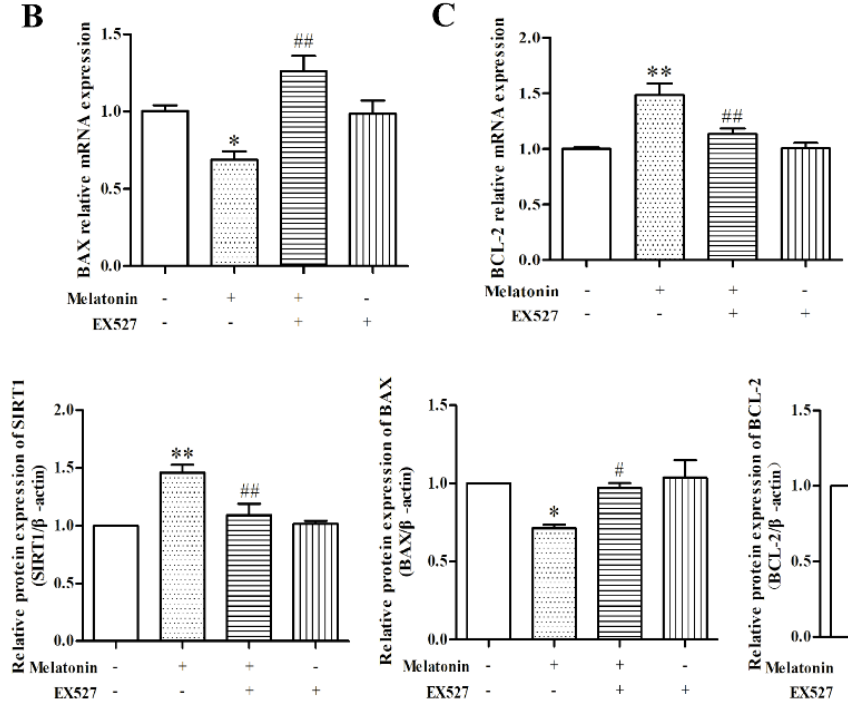

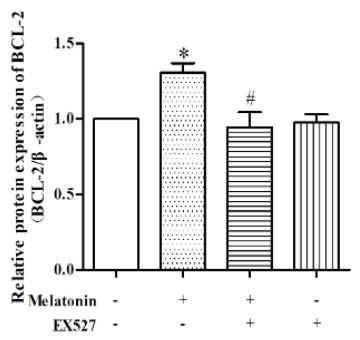

Figure 5. Effects of melatonin and EX527 on apoptosis of mouse Leydig cells. (A) The effects of melatonin and EX527 on apoptosis rate of mouse Leydig cells $(n=3)$. The four quadrants in the figure represent dead cells (Q2-1), late-stage apoptotic cells (Q2-2), viable cells (Q2-3), and early-stage apoptotic cells (Q2-4). The apoptosis rate is the sum of values from Q2-2 and Q2-4. The relative mRNA expression levels of $B A X(\mathbf{B})$ and $B C L-2(\mathbf{C})(n=3)$. (D) The relative protein expression levels of SIRT1, BAX, and BCL-2 were detected and analyzed $(n=3)$. Values are shown as mean \pm SEM. ${ }^{* *} p<0.01$ or * $p<0.05$ compared with the control group; \#\# $p<0.001$, \#\# $p<0.01$ or \# $p<0.05$ compared with melatonin-only treatment group.

\subsection{Melatonin Inhibited Oxidative Stress of Mouse Leydig Cells via a SIRT1-Dependent Mechanism}

To examine the role of SIRT1 on oxidative stress inhibited by melatonin in mouse Leydig cells, we detected the levels of ROS, MDA, 8-OHdG, SOD, and GSH-Px in mouse Leydig cells after treatment with melatonin and EX527. The results indicated that, compared to melatonin-only treatment, Ex527 significantly increased the fluorescence intensity of ROS $(p<0.05)$ (Figure 6A). Moreover, Ex527 reversed the decrease in MDA (Figure 6B) and 8-OHdG (Figure 6C) levels $(p<0.01$ ) and reversed the increase in SOD (Figure 6D) and GSH-Px (Figure 6E) levels $(p<0.01)$. These results showed that melatonin could inhibit oxidative stress via a SIRT1-dependent mechanism in mouse Leydig cells. 

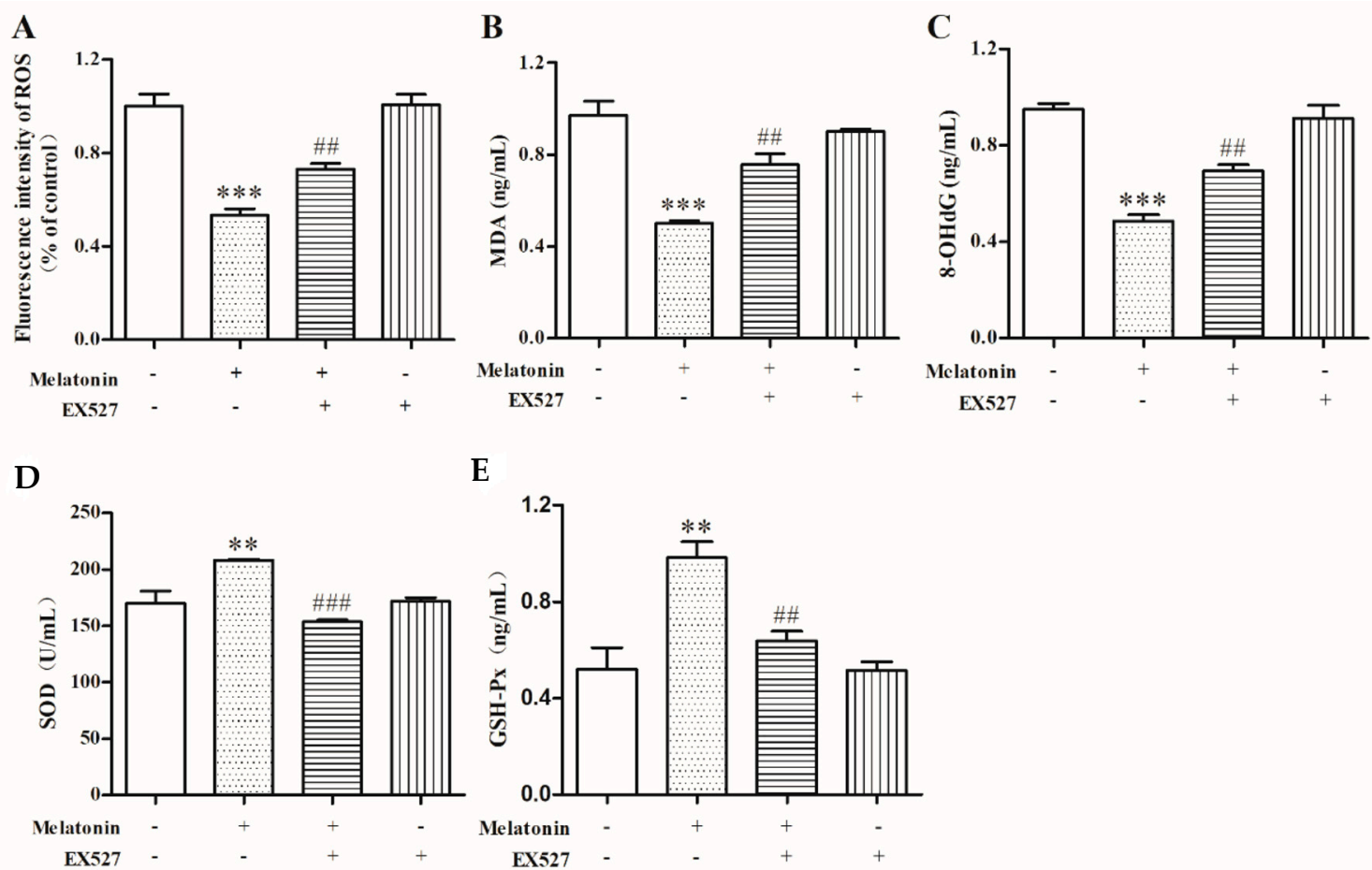

Figure 6. Effects of melatonin and EX527 on ROS, MDA, 8-OHdG, SOD, and GSH-Px in mouse Leydig cells. (A) The fluorescence intensity of ROS was measured by flow cytometry analysis $(n=3)$. The levels of MDA (B), 8-OHdG (C), SOD (D), and GSH-Px (E) were measured by a microplate reader $(n=3)$. Values are shown as mean \pm SEM. ${ }^{* * *} p<0.001$ or ${ }^{* *} p<0.01$ compared with the control group; \#\#\# $p<0.001$ or \#\# $p<0.01$ compared with melatonin-only treatment group.

\section{Discussion}

Apoptosis and oxidative damage of Leydig cells severely affect the function of the testes, leading to male infertility [6]. However, the effects of melatonin on apoptosis and oxidative stress in mouse Leydig cells have not yet been studied in detail. Our results indicated that melatonin could inhibit apoptosis and oxidative stress of mouse Leydig cells via the SIRT1 signaling pathway.

Our results showed that melatonin significantly promoted cell proliferation, manifesting as the increases in cell viability, ratio of EdU-positive cells, and related genes expression (PCNA, CCND1, and CDC42). Melatonin also prevented apoptosis of mouse Leydig cells, accompanied with an increase of mRNA and protein expression of BCL-2 and a decrease of BAX expression. In the present study, melatonin sustained BCL-2 expression and reversed bisphenol A-induced apoptosis in the rat testes and epididymal sperm [5]. The anti-apoptotic effect of melatonin has been shown in a variety of cells. For instance, in the bovine ovarian granulosa cells, melatonin not only directly inhibits apoptosis through its receptors MT1 and MT2, but also attenuates apoptosis induced by $\beta$-zearalenol and HT-2 toxin [13,30]. Additionally, in mouse cardiomyocytes, melatonin reduced the apoptosis level and the secretion of serum creatine phosphokinase and lactate dehydrogenase, up-regulated the expression of SIRT1 and anti-apoptotic gene BCL-2, and down-regulated the expression of proapoptotic genes BAX and Caspase-3 [31,32]. Similarly, melatonin could increase the mitochondrial membrane potential (MMP) and regulate apoptosis related genes expression, thereby alleviating the $\mathrm{AlCl}$-induced apoptosis in the rat spleen [33]. All of the aforementioned studies support our results that melatonin has an anti-apoptotic effect on Leydig cells.

Interestingly, melatonin at a concentration of $10 \mathrm{ng} / \mathrm{mL}$ showed the best activity, while higher concentrations had no effect. This result was also found in other studies. Treatment of mouse granulosa cells with $0.1,1,10$, and $100 \mu \mathrm{M}$ of melatonin revealed that the optimal concentration to inhibit palmitic acid-induced apoptosis was $10 \mu \mathrm{M}$, rather than $100 \mu \mathrm{M}$ [11]. In pig granulosa cells, a low concentration 
$(0.1 \mu \mathrm{M})$ of melatonin instead of the high concentration $(10 \mu \mathrm{M})$ stimulates the synthesis of estradiol and produces differentially expressed genes, which are associated with regulation of cell proliferation, cell cycle, and anti-apoptosis [34]. These results support our findings.

Furthermore, oxidative stress has been closely related to male infertility [1]. Oxidative stress is characterized by increased lipid peroxidation levels and decreased antioxidant enzyme activity, resulting in an imbalance between oxidation and antioxidation [35]. Therefore, increasing ROS content can cause oxidative stress, which leads to DNA damage and apoptosis [4]. MDA is a direct product of lipid peroxidation and $8-\mathrm{OHdG}$ is a common biomarker for DNA oxidative damage. SOD is an important scavenger for ROS and GSH-Px is also one of the indicators of anti-peroxidation ability. A previous study in Leydig cells showed that rutin reduces $\mathrm{H} 2 \mathrm{O} 2$-induced oxidative damage by decreasing ROS and MDA levels while increasing GSH, SOD, CAT, and POD activities. This indicates that rutin has strong antioxidant capacity to overcome male infertility [36]. In the present study, we found that melatonin could scavenge ROS and increase SOD and GSH-Px levels, while it decreased MDA and 8-OHdG levels. Therefore, melatonin demonstrated its antioxidative effects in Leydig cells. In addition, melatonin inhibits oxidative $\mathrm{AlCl}_{3}$-induced spleen stress in rats by scavenging $\mathrm{ROS}$ and decreasing MDA levels, while increasing the activities of SOD and CAT [33]. Similarly, melatonin enhances the levels of the antioxidant enzymes SOD, CAT, and GSH-Px, resulting in attenuation of testicular oxidative stress induced by dexamethasone [37]. Moreover, melatonin relieves DNA damage and oxidative stress of mouse granulosa cells by decreasing the 8-OHdG level, which is consistent with results in HL-60 cells [38,39]. These results strongly suggest that melatonin is an extremely effectual direct free radical scavenger and an antioxidant that acts indirectly in Leydig cells.

SIRT1, a component part of class III histone deacetylase, plays a vital function in apoptosis and oxidative stress. Melatonin is an activator of SIRT1, which was also showed in this study. Nonetheless, the function of SIRT1 in melatonin-regulated apoptosis and oxidative stress in mouse Leydig cells is unclear. Our study demonstrated that EX527, a SIRT1 inhibitor, reversed the preservation effects of melatonin on apoptosis and oxidative stress of mouse Leydig cells. Some studies support this result. The activation of SIRT1, cerebral-protection of melatonin against oxidative stress and apoptosis, relieves cerebral ischemia reperfusion injury, which was reversed by EX527 [40]. Additionally, a previous study suggested that melatonin protected against chronic obstructive pulmonary disease by preventing apoptosis and ER stress through the upregulation of SIRT1 expression in rat bronchial and alveolar epithelial cells [41]. Taken together, our results support the hypothesis that melatonin inhibits apoptosis and oxidative stress via a SIRT1-dependent mechanism in mouse Leydig cells, although the direct targets of SIRT1 in this process and experiments in vivo have not been studied.

\section{Materials and Methods}

\subsection{Cell Culture and Treatments}

The Leydig cell line TM3 was acquired from Procell (CL-0234, Wuhan, China) and chosen as the cellular model in this research study. Cells were cultured in Dulbecco's modified Eagle medium/F12 (DMEM/F-12, Gibco, Waltham, MA, USA) with 5\% super horse serum, 2.5\% fetal bovine serum (FBS), and $1 \%$ penicillin/streptomycin (Sangon Biotech, Shanghai, China). The cells were incubated in a cell incubator with $5 \% \mathrm{CO}_{2}$ at $37^{\circ} \mathrm{C}$. Melatonin (M5250-1G, Sigma-Aldrich, St. Louis, MO, USA) was liquified in alcohol at $1 \mathrm{mg} / \mathrm{mL}$ and stored at $-20^{\circ} \mathrm{C}$. Then, $1 \mathrm{mg} / \mathrm{mL}$ of melatonin was diluted in a serum-free medium to final concentrations of $1,10,100$, and $1000 \mathrm{ng} / \mathrm{mL}$ before treatment. In order to avoid the strong stimulation of horse serum, when treated with melatonin, cells were cultured in serum-free medium. To select the appropriate melatonin concentration and incubation time, cells were treated with diverse dosages of melatonin $(1,10,100$, and $1000 \mathrm{ng} / \mathrm{mL})$ at respective time periods ( $24 \mathrm{~h}, 48 \mathrm{~h}$, and $72 \mathrm{~h}$ ). The role of SIRT1 signaling on the effects of melatonin in mouse Leydig cells was explored by pretreating cells for $2 \mathrm{~h}$ with the SIRT1 inhibitor EX527 (10 $\mu \mathrm{M}$, Med Chem Express, NJ, USA). 


\subsection{Cell Viability Assay}

The Leydig cells were seeded at a density of $1 \times 10^{4}$ cells in each well of the 96-well plates in triplicate and cultured overnight. After cells were treated with melatonin, $20 \mu \mathrm{L}$ MTT $(5 \mathrm{mg} / \mathrm{mL}$ in PBS) were added to each well and then cultured for $4 \mathrm{~h}$ at $37^{\circ} \mathrm{C}$ with $5 \% \mathrm{CO}_{2}$. The supernatant was discarded and $160 \mu \mathrm{L}$ of dimethyl sulfoxide (DMSO) was supplemented to each well. The plates were agitated for $10 \mathrm{~min}$ and the absorbance was calculated at a wavelength of $490 \mathrm{~nm}$ by a microplate reader (BioTek, Winooski, VT, USA). The expression of cell viability was the magnitude of absorbance values against the control group. This experiment was performed three times independently.

\subsection{EdU Assay}

The effects of melatonin or EX527 on cell proliferation were determined using BeyoClickTM EdU cell proliferation kit with Alexa Fluor 488 (Beyotime Institute of Biotechnology, Shanghai, China). Leydig cells $\left(5 \times 10^{4}\right.$ cells per well) were cultured in triplicate in 24-well plates and treated according to experimental design. Experiments were carried out according to the kit. The proportions of EdU-positive cells were determined by a cell imaging detector (BioTek, Winooski, VT, USA) and calculated based on Gene5 software.

\subsection{Cell Apoptosis Analysis}

After they were collected and washed with PBS, cells were suspended in $1 \times$ Binding Buffer at $1 \times 10^{6}$ cells $/ \mathrm{mL}$. Next, following the manufacturer's manual of instruction, $5 \mu \mathrm{L}$ of Annexin V-FITC and $5 \mu \mathrm{L}$ of propidium iodide (PI) were added to cell suspension and incubated at room temperature for $15 \mathrm{~min}$. Cell apoptosis was detected and analyzed by flow cytometry analysis (ACEA Biosciences, Hangzhou, China) using a FITC Annexin V Apoptosis Detection Kit I (BD Biosciences, San Jose, CA, USA). Independent experiments were performed three times.

\subsection{ROS Analysis}

The ROS content was measured using ROS Detection Kit following the manufacturer's instructions (Beyotime Institute of Biotechnology, Shanghai, China). After cells were cultured and treated, cells were collected, washed with PBS, and incubated with DCFH-DA $(10 \mu \mathrm{M})$ in a cell incubator at $37^{\circ} \mathrm{C}$ for $20 \mathrm{~min}$. Then, serum-free cell culture medium was used to wash the cells three times to sufficiently remove the remaining DCFH-DA. The intensity of fluorescence was found using flow cytometry at an excitation wavelength of $488 \mathrm{~nm}$ and an emission wavelength of $525 \mathrm{~nm}$. DCF can be detected using the FITC parameter settings because the fluorescence spectrum of DCF is very similar to FITC. Independent scientific research was conducted three times.

\subsection{Quantitative Reverse Transcription Polymerase Chain Reaction (qRT-PCR) Analysis}

Total RNA was isolated from cells using Trizol reagent (Invitrogen, Carlsbad, CA, USA) and then $1 \mu \mathrm{g}$ was used to combine cDNA by a PrimeScript RT reagent Kit with gDNA Eraser (Takara, Tokyo, Japan). Real-time quantitative PCR was performed using a SYBR ${ }^{\circledR}$ Premix Ex TaqTM II (Takara, Tokyo, Japan) on a Real-Time PCR Detection System (Agilent StrataGene Mx3005P, Santa Clara, CA, USA). The primers sequences of BCL-2, BAX, PCNA, CCND1, CDC42, SIRT1, and $\beta$-actin are shown in Table 1. Relative gene expression was calculated with the $2^{-\Delta \Delta C t}$ method. 
Table 1. Information on primers of real-time quantitative PCR.

\begin{tabular}{|c|c|c|c|}
\hline Genes & Primer Sequence $\left(5^{\prime}-3^{\prime}\right)$ & Genebank No. & Size (bp) \\
\hline BCL-2 & $\begin{array}{l}\text { F: ACGGTGGTGGAGGAACTCTTCAG } \\
\text { R: GGTGTGCAGATGCCGGTTCAG }\end{array}$ & XM_021173243.1 & 168 \\
\hline BAX & $\begin{array}{l}\text { F: CGTGAGCGGCTGCTTGTCTG } \\
\text { R: ATGGTGAGCGAGGCGGTGAG }\end{array}$ & XM_021195914.1 & 128 \\
\hline PCNA & $\begin{array}{l}\text { F: TGAAGAAGGTGCTGGAGGCTCTC } \\
\text { R: AGCTGTACCAAGGAGACGTGAGAC }\end{array}$ & NM_011045.2 & 115 \\
\hline CCND1 & $\begin{array}{l}\text { F: TGGATGCTGGAGGTCTGTGAGG } \\
\text { R: GCAGGCGGCTCTTCTTCAAGG }\end{array}$ & XM_011241977.1 & 112 \\
\hline CDC42 & $\begin{array}{l}\text { F: GGCTGTCAAGTATGTGGAGTGCTC } \\
\text { R: CTGCGGCTCTTCTTCGGTTCTG }\end{array}$ & XM_021159845.1 & 111 \\
\hline SIRT1 & $\begin{array}{l}\text { F: CGTCTTGTCCTCTAGTTCCTGTG } \\
\text { R: GCCTCTCCGTATCATCTTCCAAG }\end{array}$ & NM_001159589.2 & 134 \\
\hline$\beta$-actin & $\begin{array}{l}\text { F: GTGCTATGTTGCTCTAGACTTCG } \\
\text { R: ATGCCACAGGATTCCATACC }\end{array}$ & NM_007393.5 & 174 \\
\hline
\end{tabular}

\subsection{Measurement of MDA, 8-OHdG, SOD and GSH-Px}

After cell culture and treatment, cell supernatant was collected, centrifuged at $2000 \mathrm{rpm}$ for $20 \mathrm{~min}$ at $4{ }^{\circ} \mathrm{C}$, and stored at $-20^{\circ} \mathrm{C}$ for subsequent analysis. According to the manufacturers' instructions (Shanghai Langdun Biotech, Shanghai, China), $50 \mu \mathrm{L}$ of supernatant and $50 \mu \mathrm{L}$ of biotin-labeled recognition antigen were added to each well in triplicate and incubated at $37^{\circ} \mathrm{C}$ for $30 \mathrm{~min}$. After washing with PBST, avidin-HRP was added and incubated at $37^{\circ} \mathrm{C}$ for $30 \mathrm{~min}$. The chromogen solution and the stop solution were added to each well after washing again, and the levels of MDA, GSH-Px, 8-OHdG were detected at $450 \mathrm{~nm}$ using a microplate reader. Additionally, according to the manufacturers' instructions (Shanghai Jianglai Biotech, Shanghai, China), $10 \mu \mathrm{L}$ of supernatant, $40 \mu \mathrm{L}$ of sample diluent, and $100 \mu \mathrm{L}$ of HRP-conjugate reagent were added to each well and incubated at $37^{\circ} \mathrm{C}$ for $1 \mathrm{~h}$. After washing and chromogen, the SOD level was detected at $450 \mathrm{~nm}$ using a microplate reader.

\subsection{Western Blot Analysis}

Total protein was extracted using RIPA lysis buffer (Beyotime Institute of Biotechnology, China) and then measured using the bicinchoninic acid (BCA) Protein Assay kit (Beyotime Institute of Biotechnology, Shanghai, China). The proteins were detached using SDS-PAGE and transferred to NC membranes (Merck Millipore, Darmstadt, Germany). After the membranes were blocked with Odyssey Blocking Buffer (LI-COR Biosciences, USA) for $1.5 \mathrm{~h}$ at $37^{\circ} \mathrm{C}$, the membranes were incubated with primary antibodies against BCL-2, BAX, SIRT1, and $\beta$-actin (Table 2 ) at $4{ }^{\circ} \mathrm{C}$ overnight. Then, the membranes were washed with TBST and incubated with goat anti-rabbit IgG or goat anti-mouse IgG for $1 \mathrm{~h}$ at $25^{\circ} \mathrm{C}$. The protein bands were detected by a chemisope imaging system (CLiNX Science Instruments, Shanghai, China) and the value for the control group was set as $100 \%$.

Table 2. Details of primary and secondary antibodies used for western blot in this study.

\begin{tabular}{cccc}
\hline Antibodies & Cat NO. & Source & Dilution \\
\hline BCL-2 & A11025 & ABclonal, Wuhan, China & $1: 1000$ \\
BAX & A12009 & ABclonal, Wuhan, China & $1: 1000$ \\
SIRT1 & AB110304 & Abcam, Cambridge, UK & $1: 1000$ \\
B-actin & $60008-1-1 g$ & ProteinTech, Chicago, IL, USA & $1: 5000$ \\
Goat Anti-Rabbit IgG & SA00001-2 & ProteinTech, Chicago, IL, USA & $1: 5000$ \\
Goat Anti-mouse IgG & SA00001-1 & ProteinTech, Chicago, IL, USA & $1: 5000$ \\
\hline
\end{tabular}




\subsection{Statistical Analysis}

Data were presented as mean \pm standard error of the mean (SEM). Differences between groups were ascertained by one-way analysis of variance (ANOVA) and Student's $t$ test. The $p$-values $<0.05$ were regarded to be statistically significant. All statistical analyses were performed using GraphPad Prism version 5.0 (GraphPad Prism Software, San Diego, CA, USA).

\section{Conclusions}

In conclusion, our studies demonstrated that melatonin promoted proliferation and inhibited apoptosis, while it decreased the level of ROS and oxidative stress in Leydig cells. Moreover, our results showed that melatonin exerted its anti-apoptotic and anti-oxidative effects by activating the SIRT1 signal pathway in mouse Leydig cells. Therefore, our findings provide strong evidence that melatonin has the potential to treat male infertility.

Author Contributions: Conceptualization, W.L. and J.W.; Methodology, G.X. and J.Z.; Software, H.L.; Validation, G.X., J.Z., and H.L.; Formal Analysis, G.X.; Investigation, J.Z.; Data Curation, G.X.; Writing-Original Draft Preparation, G.X.; Writing-Review \& Editing, W.L. and J.W.; Supervision, W.L. and J.W.; Project administration, W.L.; Funding Acquisition, W.L.

Funding: This work was supported by the National Key Research and Development Program of China (2016YFD0500502).

Acknowledgments: The authors thank the funds supported by 'National Key Research and Development Program of China' (Grant No. 2016YFD0500502).

Conflicts of Interest: There is no conflict of interest and all authors have approved this study for publication.

\section{References}

1. Naher, Z.U.; Ali, M.; Biswas, S.K.; Mollah, F.H.; Fatima, P.; Hossain, M.M.; Arslan, M.I. Effect of oxidative stress in male infertility. Mymensingh Med. J. 2013, 22, 136-142. [PubMed]

2. Hampl, R.; Drábková, P.; Kand'ár, R.; Stěpán, J. Impact of oxidative stress on male infertility. Ceska Gynekol. 2012, 77, 241-245. [PubMed]

3. Shukla, K.K.; Mahdi, A.A.; Rajender, S. Apoptosis, spermatogenesis and male infertility. Front. Biosci. (Elite Ed.) 2012, 4, 746-754. [CrossRef] [PubMed]

4. Wang, X.; Sharma, R.K.; Sikka, S.C.; Thomas, A.J.; Falcone, T.; Agarwal, A. Oxidative stress is associated with increased apoptosis leading to spermatozoa DNA damage in patients with male factor infertility. Fertil. Steril. 2003, 80, 531-535. [CrossRef]

5. Othman, A.I.; Edrees, G.M.; El-Missiry, M.A.; Ali, D.A.; Aboel-Nour, M.; Dabdoub, B.R. Melatonin controlled apoptosis and protected the testes and sperm quality against bisphenol A-induced oxidative toxicity. Toxicol. Ind. Health 2016, 32, 1537-1549. [CrossRef] [PubMed]

6. Wang, S.; Ren, X.; Hu, X.; Zhou, L.; Zhang, C.; Zhang, M. Cadmium-induced apoptosis through reactive oxygen species-mediated mitochondrial oxidative stress and the JNK signaling pathway in TM3 cells, a model of mouse Leydig cells. Toxicol. Appl. Pharmacol. 2019, 368, 37-48. [CrossRef]

7. Weissová, K.; Škrabalová, J.; Skálová, K.; Červená, K.; Bendová, Z.; Miletínová, E.; Kopřivová, J.; Šonka, K.; Dudysová, D.; Bartoš, A.; et al. Circadian rhythms of melatonin and peripheral clock gene expression in idiopathic REM sleep behavior disorder. Sleep Med. 2018, 52, 1-6. [CrossRef]

8. Tamura, H.; Kawamoto, M.; Sato, S.; Tamura, I.; Maekawa, R.; Taketani, T.; Aasada, H.; Takaki, E.; Nakai, A.; Reiter, R.J.; et al. Long-term melatonin treatment delays ovarian aging. J. Pineal Res. 2017, 62, e12381. [CrossRef]

9. Li, R.; Luo, X.; Li, L.; Peng, Q.; Yang, Y.; Zhao, L.; Ma, M.; Hou, Z. The Protective Effects of Melatonin Against Oxidative Stress and Inflammation Induced by Acute Cadmium Exposure in Mice Testis. Biol. Trace Elem. Res. 2016, 170, 152-164. [CrossRef]

10. Carloni, S.; Favrais, G.; Saliba, E.; Albertini, M.C.; Chalon, S.; Longini, M.; Gressens, P.; Buonocore, G.; Balduini, W. Melatonin modulates neonatal brain inflammation through endoplasmic reticulum stress, autophagy, and miR-34a/silent information regulator 1 pathway. J. Pineal Res. 2016, 61, 370-380. [CrossRef] 
11. Chen, Z.; Lei, L.; Wen, D.; Yang, L. Melatonin attenuates palmitic acid-induced mouse granulosa cells apoptosis via endoplasmic reticulum stress. J. Ovarian Res. 2019, 12, 43. [CrossRef] [PubMed]

12. Zhang, Y.; Liu, X.; Bai, X.; Lin, Y.; Li, Z.; Fu, J.; Li, M.; Zhao, T.; Yang, H.; Xu, R.; et al. Melatonin prevents endothelial cell pyroptosis via regulation of long noncoding RNA MEG3/miR-223/NLRP3 axis. J. Pineal Res. 2018, 64, e12449. [CrossRef] [PubMed]

13. Yang, F.; Li, L.; Chen, K.; Li, C.; Wang, Y.; Wang, G. Melatonin alleviates $\beta$-zearalenol and HT-2 toxin-induced apoptosis and oxidative stress in bovine ovarian granulosa cells. Environ. Toxicol. Pharmacol. 2019, 68, 52-60. [CrossRef] [PubMed]

14. Hibaoui, Y.; Roulet, E.; Ruegg, U.T. Melatonin prevents oxidative stress-mediated mitochondrial permeability transition and death in skeletal muscle cells. J. Pineal Res. 2009, 47, 238-252. [CrossRef] [PubMed]

15. He, R.; Cui, M.; Lin, H.; Zhao, L.; Wang, J.; Chen, S.; Shao, Z. Melatonin resists oxidative stress-induced apoptosis in nucleus pulposus cells. Life Sci. 2018, 199, 122-130. [CrossRef] [PubMed]

16. Lv, Y.; Zhang, P.; Guo, J.; Zhu, Z.; Li, X.; Xu, D.; Zeng, W. Melatonin protects mouse spermatogonial stem cells against hexavalent chromium-induced apoptosis and epigenetic histone modification. Toxicol. Appl. Pharmacol. 2018, 340, 30-38. [CrossRef] [PubMed]

17. Ozen, O.A.; Kus, M.A.; Kus, I.; Alkoc, O.A.; Songur, A. Protective effects of melatonin against formaldehyde-induced oxidative damage and apoptosis in rat testes: An immunohistochemical and biochemical study. Syst. Biol. Reprod. Med. 2008, 54, 169-176. [CrossRef] [PubMed]

18. Guo, Y.; Sun, J.; Li, T.; Zhang, Q.; Bu, S.; Wang, Q.; Lai, D. Melatonin ameliorates restraint stress-induced oxidative stress and apoptosis in testicular cells via NF-kB/iNOS and Nrf2/HO-1 signaling pathway. Sci. Rep. 2017, 7, 9599. [CrossRef]

19. Bahrami, N.; Goudarzi, M.; Hosseinzadeh, A.; Sabbagh, S.; Reiter, R.J.; Mehrzadi, S. Evaluating the protective effects of melatonin on di(2-ethylhexyl) phthalate-induced testicular injury in adult mice. Biomed. Pharmacother. 2018, 108, 515-523. [CrossRef]

20. Mohammadghasemi, F.; Jahromi, S.K. Melatonin ameliorates testicular damages induced by nicotine in mice. Iran. J. Basic Med. Sci. 2018, 21, 639-644.

21. Persengiev, S.; Kehajova, J. Inhibitory action of melatonin and structurally related compounds on testosterone production by mouse Leydig cells in vitro. Cell. Biochem. Funct. 1991, 9, 281-286. [CrossRef] [PubMed]

22. Qin, F.; Zhang, J.; Zan, L.; Guo, W.; Wang, J.; Chen, L.; Cao, Y.; Shen, O.; Tong, J. Inhibitory effect of melatonin on testosterone synthesis is mediated via GATA-4/SF-1 transcription factors. Reprod. Biomed. Online 2015, 31, 638-646. [CrossRef] [PubMed]

23. Xu, R.Y.; Xu, X.W.; Deng, Y.Z.; Ma, Z.X.; Li, X.R.; Zhao, L.; Qiu, L.J.; Liu, H.Y.; Chen, H.P. Resveratrol attenuates myocardial hypoxia/reoxygenation-induced cell apoptosis through DJ-1-mediated SIRT1-p53 pathway. Biochem. Biophys. Res. Commun. 2019, 514, 401-406. [CrossRef] [PubMed]

24. Domazetovic, V.; Marcucci, G.; Pierucci, F.; Bruno, G.; Di Cesare Mannelli, L.; Ghelardini, C.; Brandi, M.L.; Iantomasi, T.; Meacci, E.; Vincenzini, M.T. Blueberry juice protects osteocytes and bone precursor cells against oxidative stress partly through SIRT1. FEBS Open Bio 2019, 9, 1082-1096. [PubMed]

25. Brunet, A.; Sweeney, L.B.; Sturgill, J.F.; Chua, K.F.; Greer, P.L.; Lin, Y.; Tran, H.; Ross, S.E.; Mostoslavsky, R.; Cohen, H.Y.; et al. Stress-dependent regulation of FOXO transcription factors by the SIRT1 deacetylase. Science 2004, 303, 2011-2015. [CrossRef] [PubMed]

26. Zhao, L.; An, R.; Yang, Y.; Yang, X.; Liu, H.; Yue, L.; Li, X.; Lin, Y.; Reiter, R.J.; Qu, Y. Melatonin alleviates brain injury in mice subjected to cecal ligation and puncture via attenuating inflammation, apoptosis, and oxidative stress: The role of SIRT1 signaling. J. Pineal Res. 2015, 59, 230-239. [CrossRef]

27. Yu, L.; Sun, Y.; Cheng, L.; Jin, Z.; Yang, Y.; Zhai, M.; Pei, H.; Wang, X.; Zhang, H.; Meng, Q.; et al. Melatonin receptor-mediated protection against myocardial ischemia/reperfusion injury: Role of SIRT1. J. Pineal Res. 2014, 57, 228-238. [CrossRef]

28. Yu, L.; Liang, H.; Dong, X.; Zhao, G.; Jin, Z.; Zhai, M.; Yang, Y.; Chen, W.; Liu, J.; Yi, W.; et al. Reduced silent information regulator 1 signaling exacerbates myocardial ischemia-reperfusion injury in type 2 diabetic rats and the protective effect of melatonin. J. Pineal Res. 2015, 59, 376-390. [CrossRef]

29. Zhang, W.X.; He, B.M.; Wu, Y.; Qiao, J.F.; Peng, Z.Y. Melatonin protects against sepsis-induced cardiac dysfunction by regulating apoptosis and autophagy via activation of SIRT1 in mice. Life Sci. 2019, 217, 8-15. [CrossRef] 
30. Wang, S.J.; Liu, W.J.; Wu, C.J.; Ma, F.H.; Ahmad, S.; Liu, B.R.; Han, L.; Jiang, X.P.; Zhang, S.J.; Yang, L.G. Melatonin suppresses apoptosis and stimulates progesterone production by bovine granulosa cells via its receptors (MT1 and MT2). Theriogenology 2012, 78, 1517-1526. [CrossRef]

31. Chen, Z.; Chua, C.C.; Gao, J.; Chua, K.W.; Ho, Y.S.; Hamdy, R.C.; Chua, B.H. Prevention of ischemia/reperfusion-induced cardiac apoptosis and injury by melatonin is independent of glutathione peroxdiase 1. J. Pineal Res. 2009, 46, 235-241. [CrossRef] [PubMed]

32. Han, D.; Wang, Y.; Chen, J.; Zhang, J.; Yu, P.; Zhang, R.; Li, S.; Tao, B.; Qiu, Y.; Xu, M.; et al. Activation of melatonin receptor 2 but not melatonin receptor 1 mediates melatonin-conferred cardioprotection against myocardial ischemia/reperfusion injury. J. Pineal Res. 2019, 67, e12571. [CrossRef] [PubMed]

33. Yu, H.; Zhang, J.; Ji, Q.; Yu, K.; Wang, P.; Song, M.; Cao, Z.; Zhang, X.; Li, Y. Melatonin alleviates aluminium chloride-induced immunotoxicity by inhibiting oxidative stress and apoptosis associated with the activation of Nrf2 signaling pathway. Ecotoxicol. Environ. Saf. 2019, 173, 131-141. [CrossRef] [PubMed]

34. Liu, Y.; Yang, Y.; Li, W.; Ao, H.; Zhang, Y.; Zhou, R.; Li, K. Effects of melatonin on the synthesis of estradiol and gene expression in pig granulosa cells. J. Pineal Res. 2019, 66, e12546. [CrossRef] [PubMed]

35. Luo, X.; Jia, S.; Ma, Q.; Zhong, M.; Gao, P.; Yu, Z.; Zhang, Y. Suppressive effects of subchronic aluminum overload on the splenic immune function may be related to oxidative stress in mice. Biol. Trace Elem. Res. 2014, 157, 249-255. [CrossRef]

36. Sun, J.; Wang, H.; Liu, B.; Shi, W.; Shi, J.; Zhang, Z.; Xing, J. Rutin attenuates $\mathrm{H}_{2} \mathrm{O}_{2}$-induced oxidation damage and apoptosis in Leydig cells by activating PI3K/Akt signal pathways. Biomed. Pharmacother. 2017, 88, 500-506. [CrossRef]

37. Mukherjee, A.; Haldar, C.; Vishwas, D.K. Melatonin prevents dexamethasone-induced testicular oxidative stress and germ cell apoptosis in golden hamster, Mesocricetus auratus. Andrologia 2015, 47, 920-931. [CrossRef]

38. Tanabe, M.; Tamura, H.; Taketani, T.; Okada, M.; Lee, L.; Tamura, I.; Maekawa, R.; Asada, H.; Yamagata, Y.; Sugino, N. Melatonin protects the integrity of granulosa cells by reducing oxidative stress in nuclei, mitochondria, and plasma membranes in mice. J. Reprod. Dev. 2015, 61, 35-41. [CrossRef]

39. Sun, Y.; Zong, L.; Gao, Z.; Zhu, S.; Tong, J.; Cao, Y. Mitochondrial DNA damage and oxidative damage in HL-60 cells exposed to 900MHz radiofrequency fields. Mutat. Res. 2017, 797, 7-14. [CrossRef]

40. Yang, Y.; Jiang, S.; Dong, Y.; Fan, C.; Zhao, L.; Yang, X.; Li, J.; Di, S.; Yue, L.; Liang, G.; et al. Melatonin prevents cell death and mitochondrial dysfunction via a SIRT1-dependent mechanism during ischemic-stroke in mice. J. Pineal Res. 2015, 58, 61-70. [CrossRef]

41. He, B.; Zhang, W.; Qiao, J.; Peng, Z.; Chai, X. Melatonin protects against COPD by attenuating apoptosis and endoplasmic reticulum stress via upregulating SIRT1 expression in rats. Can. J. Physiol. Pharmacol. 2019, 97, 386-391. [CrossRef] [PubMed]

Sample Availability: Not available.

(C) 2019 by the authors. Licensee MDPI, Basel, Switzerland. This article is an open access article distributed under the terms and conditions of the Creative Commons Attribution (CC BY) license (http://creativecommons.org/licenses/by/4.0/). 